\title{
Computer Modeling of the Turbulent Natural Gas Combustion in a Cyclone-Calciner Furnace
}

\author{
Roman Havryliv \\ Department of chemical engineering \\ Lviv Polytechnic National University \\ Lviv, Ukraine \\ havrilivroman@gmail.com
}

\author{
Volodymyr Maystruk \\ Department of design and operatin of machines \\ Lviv Polytechnic National University \\ Lviv, Ukraine \\ vmaistruk@gmail.com
}

\author{
Iryna Kostiv \\ Department of chemical engineering \\ Lviv Polytechnic National University \\ Lviv, Ukraine \\ kostiv.irina@gmail.com
}

\begin{abstract}
The aim of this study is a computer modeling of the natural gasturbulent combustion in an industrial cyclonecalciner furnace. Computer modeling is performed by using Ansys Fluent computational fluid dynamics software with Reynolds-averaged Navier-Stokes (RANS) turbulence model coupled with Eddy-Dissipation concept (EDM) and discrete ordinates radiate heat transfer model.

Modeling results are compared with experimental data and it's shown the influence of the mixing rate constant of EddyDissipation model on the flame temperature peaks in the furnace domain. Based on the presented results, the practical recommendations have been developed for the ANSYS Fluent software package application to industrial combustion process simulation in cyclone furnace.
\end{abstract}

Index Terms-computer combustion;cyclone furnace

modeling;

turbulent

\section{INTRODUCTION}

There are many industrial processes in chemical technology where combustion plays a decisive role. These are the cement and lime production processes, roasting ore and many others. In addition, combustion processes are widely used to generate steam, heat and energy for most manufacturing processes. Studying industrial combustion is of immense practical importance from ecological and technological aspects.

Currently, it is necessary to ensure minimal time and economic resources for the design of industrial furnaces or burners. The most modern and powerful tool that can be used to study and analyze combustion processes in industrial installations is a computer simulation.
The present study shows the computer simulation results of turbulent methane-air combustion in cycloncalciner furnace by using Ansys Fluent computational fluid dynamics software based on Eddy-Dissipation concept that is most commonly used in chemical engineering.

\section{II.PROBLEM DESCRIPTION}

In the previous study, computation fluid dynamic (CFD) modeling of methane-air combustion in the cyclone-calciner furnace has been carried [1]. The aim was validation and verification of the capabilities using a numerical method to the investigation of combustion processes in the furnace. The study included effects of severalReynolds-averaged NavierStokes (RANS) turbulence models and combustion models that are presented by ANSYS FLUENT. From these results, the temperature fields were extracted on the vertical cross section of the furnace. These results were analyzed in detail and agreed fairly well with experimental data.

Results suggest that the Realizable k- $\varepsilon$ turbulence model coupled with Non-Premixed combustion model provided reasonably accurate predictions. The realizable $\mathrm{k}-\varepsilon$ model exhibits better performance in the prediction of temperature peak in comparison with other turbulence models.For EddyDissipation modelit has been observed the higher temperatures in the furnace than those predicted for the proposed NonPremixed model.

However, the Non-Premixed combustion model cannot be used to simulate combustion processes with particles of the discrete phase. This creates serious problems for the further using of the CFD approach for combustion modeling in an industrial cyclone furnace. 
Therefore, the same modeling approach based on EddyDissipation model but with different values mixing rate constant has been adopted in the present work.

\section{SIMULATION APPROACH}

Modelled cyclone-calciner furnace is shown in Fig. 1, a, b. The combustion processes take place in a conical section 2 of the furnace, consisting of a $0.8 \mathrm{~m}$ diameter cylinder with $4,4 \mathrm{~m}$ height.

The air is introduced into the calciner in two places. The primary air flow enters the burner 3 through the pipe 4 and additional flows enter the conical part of the calciner-furnace via two pipes 5 tangentially. The additional flows are inlet in the conical part of the calciner through the blades 9 where the air creates a swirling of the flow. This mode of the furnace was described in [2] and called an additional mode of the apparatus.

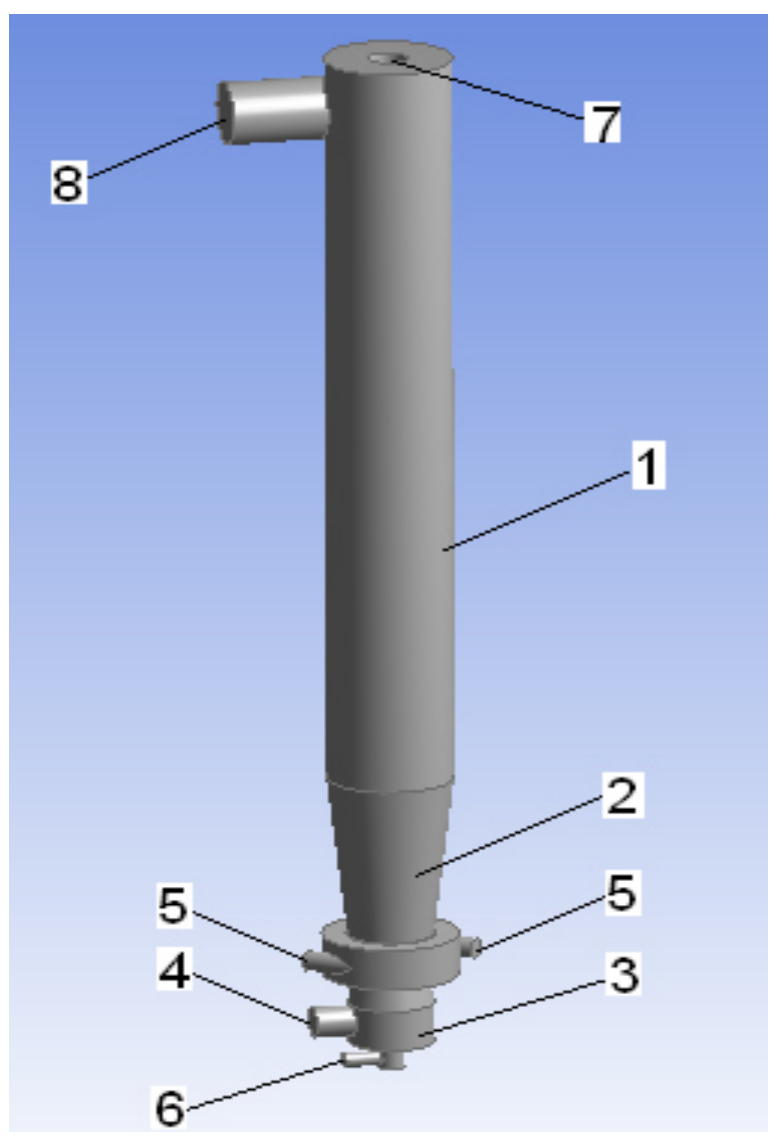

a

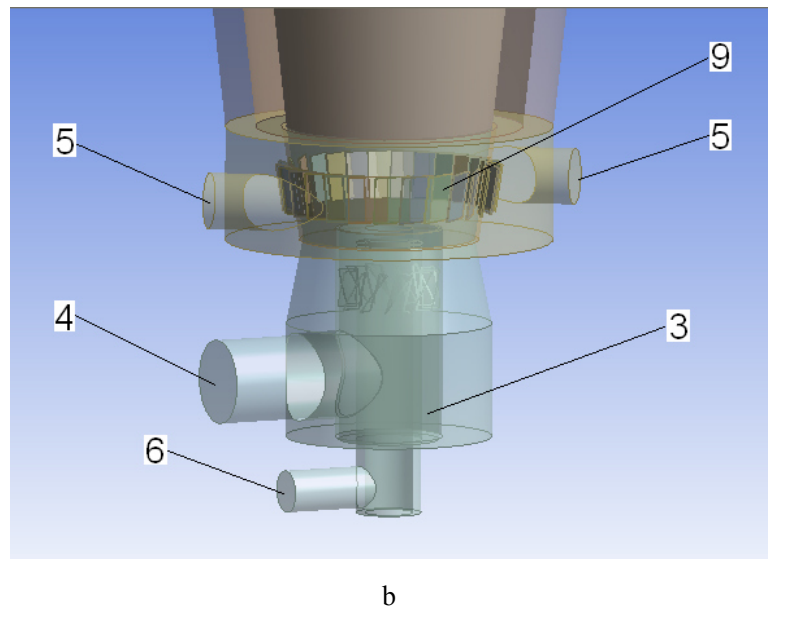

Figure. 1. Cyclone-calciner furnace geometry: a - general view of furnace; $\mathrm{b}$ - burner location

The fuel (methane) enters the burner through the inlet tube 6 which has a circular shape. Natural gas and air run into a burning chamber and are mixed up. In the burner, the burnt fuel and gases are derived through a conical section 2 and cylindrical section 1 . The combustion products such as $\mathrm{CO} 2$, and other gases go out through the outlet tube 8 with a diameter of $0.485 \mathrm{~m}$. The total furnace volume is $3,4 \mathrm{~m} 3$.

All the geometric data and the initial and boundary conditions were supplied by "Pustomyty lime plant", Ukraine.

To simulate the turbulent methane-air combustion the most popular approach is eddy-dissipation model based on the work of Magnussen and Hjertager [3,4]. It is a turbulent-chemistry reaction model where the reaction rate will be determined assuming that turbulent mixing is the rate-limiting process, with the turbulence-chemistry interaction modelled.

The net rate of production of species $i$ due to reaction $r$, $\mathrm{Ri}, \mathrm{r}$, is given by the smaller (i.e., limiting value) of the two equations below:

$$
\begin{aligned}
& R_{i}=v_{i, k}^{\prime} M_{i} A \rho \frac{\varepsilon}{k}\left(\frac{Y_{R}}{v_{R, k}^{\prime} M_{R}}\right) \\
& R_{i}=v_{i, k}^{\prime} M_{i} A B \rho \frac{\varepsilon}{k}\left(\frac{\Sigma_{P} Y_{R}}{\sum_{j^{\prime}}^{N} v_{j^{\prime}, k}^{\prime \prime} M_{j^{\prime}}}\right)
\end{aligned}
$$

Where:

$A$ is a an empirical constant equal to 4.0 ;

$B$ is an empirical constant equal to 0.5 ;

$M$ is a molecular weight

$Y_{P}$ is the mass fraction of any product species, $P$;

$Y_{R}$ is the mass fraction of a particular reactant, $R$; $\varepsilon$ is the turbulent dissipation rate $\left(\mathrm{m}^{2} \mathrm{~s}^{-3}\right)$;

$K$ is the turbulent kinetic energy per unit mass $(\mathrm{J} / \mathrm{kg})$.

$v_{i}^{\prime}, v_{j}^{\prime \prime}$ is the stoichiometric coefficient for reactant $i$ and product $j$ in reaction 
The value of theMixing rate constant of EDM was set us 4, $2,1.2,0.6$. To simulate radiate heat transfer the discrete ordinates model was used.

The combustion will be modelled using a global one-step reaction mechanism assuming complete conversion of the fuel (methane) to $\mathrm{CO}_{2}$ and $\mathrm{H}_{2} \mathrm{O}$. This reaction will be defined in terms of stoichiometric coefficients, formation enthalpies, and parameters that control the reaction rate. This mechanism gives the average value of enthalpy and is applicable to estimate the distribution of the main products of combustion $\left(\mathrm{CO}_{2}, \mathrm{H}_{2} \mathrm{O}\right)$ and temperature fields. Its advantage is simplicity and maximum simulation rate.

At the core of the CFD furnace model, there are the basic equations of hydrodynamics, namely the continuity equation (1), it expresses the law conservation of mass in the elementary volume, and the equation of momentum conservation (2). These equations represent the basic model of the medium flow [16].

$$
\begin{gathered}
\frac{\partial p}{\partial t}+\nabla(\rho \vec{v})=S_{m} \\
\frac{\partial}{\partial t}(\rho \vec{v})+\nabla(\rho \vec{v} \vec{v})=-\nabla p+\nabla(\vec{\tau})+\rho \vec{g}+\vec{F}
\end{gathered}
$$

where $\rho$-density, $v$-velocity, $S_{m}-$ is the mass added to the continuous phase from the dispersed second phase, $\tau$ - stress tensor, $p$ - static pressure, $F$ - external body force, $\rho g-$ the gravitational body force. To simulate the turbulence flow the "Realizable "k- $\varepsilon$ model of turbulence was used.

The SIPMLE algorithm was chosen for the coupling between the velocity and the pressure. For all simulations a Second Order Upwind scheme was used for the conservation equation of momentum, turbulent kinetic energy, turbulent dissipation rate, mean mixture fraction. The Standard scheme is used for interpolation methods for pressure. The convergence criterion is the summation of residual mass sources less than $10^{-3}$ for the other terms of the transport equations and is $10^{-6}$ for energy equation.

\section{RESULTS AND DISCUSSION}

The temperature distribution in a vertical cross-section through the cyclone furnace is shown in Fig. 2 and Fig. 3 for the both cases of combustion models, respectively. The modeling results in Fig. 2 are shown according to the standard scheme of eddy dissipation model (EDM) and the coefficients $\mathrm{A}$ and $\mathrm{B}$ were equal to 4 and 0.5 , respectively. The modeling results in Fig. 3 are shown for the lower values of mixing rate constant.

It is observed that the modeled maximum temperature calculated for the turbulent diffusion flame using the EddyDissipation concept with lower values of the mixing rate constant gives $2330 \mathrm{~K}$. In comparison with the standard EddyDissipation model, the peak temperature is lower by $50 \mathrm{~K}$.

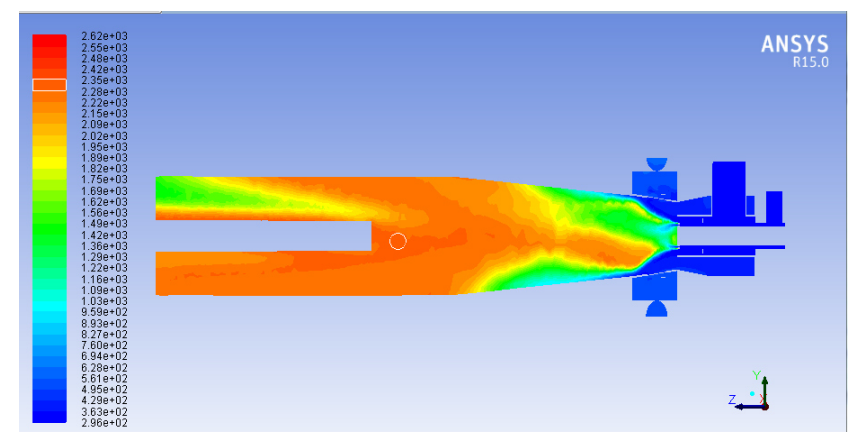

Figure. 2. Temperature profile in a vertical cross section through the furnace based on Eddy-Dissipation combustion model

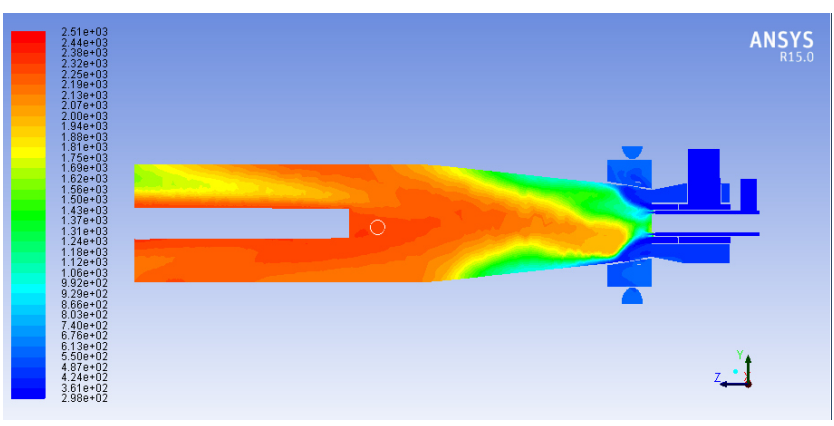

Figure 3. Temperature profile in a vertical cross section through the furnace based on Eddy-Dissipation combustion model

Thus, the mixing of fuel and oxidant flows in furnace burner plays a significantly larger role than a chemical reaction in the turbulent combustion process.

\section{CONCLUSION}

Using the EDM model with the lower values of the Mixing rate constant predicts a peak temperature in the working zone of the furnace lower in comparison with the standard model. But the discrepancy with the experimental data is still high.

These discrepancies indicate that the computed and measured furnace peak temperatures are not the cases with the current model.

Further modeling efforts will therefore be performed, first by adjusting the model boundary conditions and choosing correct turbulence model to predict more correctly the furnace temperature in the work zone.

\section{REFERENCES}

[1] Havryliv R. Development of Combustion Model in the Industrial Cyclone-Calciner Furnace Using CFD-Modeling [Text]/ R. Havrylivand V. Maystruk // Ch\&ChT. 2017.- vol. 11, No. 1. - p. 71-80.

[2] Havryliv R. Development of a numerical model for gas-solid flow in the industrial cyclone-caciner furnace [Text]/ R. Havryliv, V. Maystruk, V. Biliak //EEJET.- 2015.- vol. 3/8 (75).- p.14-21.

[3] Magnussen B. F. and Hjertager B. H. 16-th Symp. on Combustion. The Combustion Institute, USA, Pittsburgh, 1976, 719.

[4] Peters N. Turbulent Combustion. Cambridge Monographs on Mechanics. Cambridge University Press, Cambridge, 2014. 